\title{
Effect of smokeless tobacco products on human oral bacteria growth and viability
}

Min Liu ${ }^{\mathrm{a}, \mathrm{b}}$, Jinshan Jin ${ }^{\mathrm{a}}$, Hongmiao Pan ${ }^{\mathrm{a}, \mathrm{c}}$, Jinhui Feng ${ }^{\mathrm{a}, \mathrm{d}}$, Carl E. Cerniglia ${ }^{\mathrm{a}}$, Maocheng Yang ${ }^{\mathrm{e} *}$, Huizhong Chen ${ }^{\mathrm{a} *}$

Running title: Impact of smokeless tobacco exposure on oral bacteria

Key Words: Smokeless tobacco, toxicology, oral bacteria, cell viability, tobacco-specific Nnitrosamines 
Abstract

To evaluate the toxicity of smokeless tobacco products (STPs) on oral bacteria, seven smokeless tobacco aqueous extracts (STAEs) from major brands of STPs and three tobacco-specific Nnitrosamines (TSNAs) were used in a growth and viability test against 38 oral bacterial species or subspecies. All seven STAEs showed concentration-dependent effects on the growth and viability of tested oral bacteria under anaerobic culture conditions, although there were strain-to-strain variations. In the presence of $1 \mathrm{mg} / \mathrm{ml}$ STAEs, the growth of 4 strains decreased over $0.32-2.14 \log _{10}$ fold, while 14 strains demonstrated enhanced growth of $0.3-1.76 \log _{10}$ fold, and the growth of 21 strains was not significantly affected. In the presence of $10 \mathrm{mg} / \mathrm{ml}$ STAEs, the growth of 17 strains was inhibited 0.3$2.11 \log _{10}$ fold, 18 strains showed enhanced growth of $0.3-0.97 \log _{10}$ fold, and 4 strains were not significantly affected. In the presence of $50 \mathrm{mg} / \mathrm{ml}$ STAEs, the growth of 32 strains was inhibited 0.3$2.96 \log _{10}$ fold, 8 strains showed enhanced growth of $0.3-1.0 \log _{10}$ fold, and 2 strains were not significantly affected. All seven STAEs could promote the growth of 4 bacterial strains, including Eubacterium nodatum, Peptostreptococcus micros, Streptococcus anginosus, and Streptococcus constellatus. Exposure to STAEs modulated the viability of some bacterial strains, with 21.1-66.5\% decrease for 4 strains at $1 \mathrm{mg} / \mathrm{ml}, 20.3-85.7 \%$ decrease for 10 strains at $10 \mathrm{mg} / \mathrm{ml}, 20.0-93.3 \%$ decrease for 27 strains at $50 \mathrm{mg} / \mathrm{ml}$, and no significant effect for 11 strains at up to $50 \mathrm{mg} / \mathrm{ml}$. STAEs from snuffs inhibited more tested bacterial strains than those from snus indicating that the snuffs may be more toxic to the oral bacteria than snus. For TSNAs, cell growth and viability of 34 tested strains were not significantly affected at up to $100 \mu \mathrm{g} / \mathrm{ml}$; while the growth of $P$. micros was enhanced $0.31-0.54$ $\log _{10}$ fold; the growth of Veillonella parvula was repressed $0.33-0.36 \log _{10}$ fold; and the cell viabilities of 2 strains decreased 56.6-69.9\%. The results demonstrate that STAEs affected the growth of some types of oral bacteria, which may affect the healthy ecological balance of oral bacteria in humans. On the other hand, TSNAs did not significantly affect the growth of the oral bacteria. 
47 The prevalence of smokeless tobacco products (STPs) is a public health issue especially among youth and young adult males in the United States. It is estimated that $2.6 \%$ of US adults are current users of smokeless tobacco products [1]. Moreover, a separate survey reports that $9.9 \%$ high school males were current users of smokeless tobacco products in 2014. (www.cdc.gov/tobacco/data_statistics/fact_sheets/smokeless/use_us/index.htm). Major types of smokeless tobacco products in the US market include snuff, snus, chewing tobacco, and some dissolvables (http://www.cancer.org/cancer/cancercauses/tobaccocancer/smokeless-tobacco) [2]. Use of STPs can cause numerous health problems, including gingival and periodontal inflammation [3], oral, esophageal and pancreatic cancer $[4,5]$, and cardiovascular disease associated with hematogenous spread of oral bacteria [2]. Nicotine is one of the major alkaloids in STPs and exposure of nicotine leads to addiction. Nicotine can be absorbed and enter the bloodstream through oral exposure, thus use of STPs can cause nicotine addiction similar to smoking tobacco [4, 6, 7].

In the human oral cavity, there are more than 700 bacterial species or phylotypes, as identified by cultivation or culture-independent molecular approaches [8, 9]. The commensal bacteria play an important role in maintaining oral and systemic health [10-12]. Disruption of the ecology of oral bacteria might cause oral infectious and systemic diseases [13, 14]. An important question is whether oral bacteria can convert constituents in smokeless tobacco to more or less genotoxic and carcinogenetic substances. A few studies have investigated the effects of nicotine on growth of oral bacteria. Keene and Johnson [15] indicated a biphasic, dosage-dependent effect of nicotine on the growth of Streptococcus mutans. In addition, the concentration of nicotine $\left(10^{-3} \mathrm{M}\right)$ in the saliva of smokeless tobacco users could stimulate growth of $S$. mutans and possibly place the user at increased risk for dental caries. Recently, Huang et al. [16] found that addition of nicotine enhanced biofilm formation and biofilm metabolic activity of $S$. mutans, which suggested that smoking can increase the 
development of caries by fostering increased formation of $S$. mutans biofilms on tooth surfaces. An in vitro study provided evidence of stimulated growth of $S$. mutans and S. sanguinis in the presence of smokeless tobacco extracts $[17,18]$. Extracts from chewing tobacco with high sugar content can increase the growth of Lactobacillus casei $[18,19]$. Another study indicated that extracts of STPs may serve as a growth substrate for S. mutans, S. salivarius and S. sanguinis [20]. Ayo-Yusuf et al. found that low concentrations of STPs on the South African market didn't inhibit oral bacterial flora [21]. All these results suggest that STPs might affect the growth of oral bacteria. However, the data on the effects of STPs on oral bacterial growth are limited, and few oral bacteria were investigated in these studies.

STPs contain more than 30 carcinogens [22], such as tobacco-specific N-nitrosamines (TSNAs), polycyclic aromatic hydrocarbons (PAHs), aldehydes, metals, and a variety of other chemical constituents [6]. Among these carcinogens, TSNAs are considered some of the most important due to the combination of abundance and strong carcinogenicity [23, 24]. Two major TSNAs, N'nitrosonornicotine (NNN) and 4-(methylnitrosoamino)-1-(3-pyridinyl)-1-butanone (NNK) are known risk factors for human cancer [23]. Some studies report that the production of TSNAs increased during the fermentation process [25], indicating that oral bacteria might affect the genotoxicity and carcinogenesis of STPs.

In this study, we investigated the effects of STAEs from seven major brands of STPs in the US market and three major TSNAs, including NNN, NNK and 4-(methylnitrosoamino)-1-(3-pyridinyl)-1butanol (NNAL, a major metabolite of NNK) on 38 oral bacterial species/subspecies.

\section{Methods and Materials}

\subsection{Materials}

About 50 cans of each of seven most popular brands of STPs were purchased from local stores 
94 in Little Rock, Arkansas between 2012 and 2014, including two major brands of Snus named as Snus 1 95 (Camel Snus Large Robust) and 2 (Marlboro Snus Mint) [26], and five major brands of moist snuff 96 named as Snuff 3 (Copenhagen Snuff Original Fine Cut), 4 (Copenhagen Long Cut Wintergreen), 5

97 (Grizzly Long Cut Premium Wintergreen), 6 (Skoal Long Cut Classic Wintergreen), and 7 (Skoal 98 Banditis Wintergreen) [26, 27]. The most popular brands of snus and moist snuff were selected in order 99 to ensure that the results described herein covered a significant portion of the market for these kinds of 100 STPs. NNN, NNK and NNAL were purchased from Sigma-Aldrich Company (St. Louis, MO). The 101 samples of the smokeless tobacco products were stored at $-20^{\circ} \mathrm{C}$. The LIVE/DEAD BacLight bacterial 102 viability and counting kit was purchased from Life Technologies (Grand Island, NY).

\subsection{Preparation of smokeless tobacco aqueous extracts (STAEs)}

105

The extraction of smokeless tobacco aqueous extracts (STAEs) was done according to previous studies [20, 28, 29] with some modifications. Briefly, $5 \mathrm{~g}$ of STP was placed in a 50-ml centrifuge tube containing $25 \mathrm{ml}$ Milli-Q water and sonicated in a Branson 3200 ultrasonic cleaner for $1 \mathrm{~h}$, and then the mixtures were centrifuged at $12,000 \times g$ for $1 \mathrm{~h}$ at $4{ }^{\circ} \mathrm{C}$. The supernatants were adjusted to $\mathrm{pH} 7.0$ and filtered through $0.2 \mu \mathrm{m}$ pore size filter. The filtered extracts were lyophilized, using a Labconco

110 FreeZone Console Freeze Dry Systems (Kansas City, MO). The dried extracts were weighted and re111 suspended to 10,100 and $500 \mathrm{mg} / \mathrm{ml}$ stock solutions in Milli-Q water.

\subsection{Detection of nicotine contents}

114 Nicotine content in STAEs was detected by high-performance liquid chromatography (HPLC). 115 The HPLC system (Agilent Technologies 1200 Series, Santa Clara, CA) consisted of G1379B degasser, 
116 G1312A binary pump, G1329A autosampler, and G1315D Diode Array Detector. The analytical

117 column used as the stationary phase was a LiChroCART, Purospher STAR RP-18 endcapped (125 cm

$118 \times 4 \mathrm{~mm}$ i.d., $5 \mu \mathrm{m}$ particle size) (Merck Millipore, Billerica, MA). The mobile phase was a mixture of

$1190.272 \mathrm{~g}$ of $\mathrm{KH}_{2} \mathrm{PO}_{4}, 0.184 \mathrm{~g}$ of sodium $n$-heptane sulfonate, $820 \mathrm{ml}$ of water (HPLC-grade), and $180 \mathrm{ml}$ 120 of methanol (HPLC-grade). The $\mathrm{pH}$ of the mobile phase was adjusted by drop wise addition of ortho121 phosphoric acid $(\mathrm{pH} \approx 3.2)$. The flow rate used was $1.0 \mathrm{ml} / \mathrm{min}$ and the injection volume of $1 \mu \mathrm{l}$. The 122 wavelength was fixed at $254 \mathrm{~nm}$ [30].

$124 \quad 2.4$ Bacterial strains and growth conditions

125 Twenty-nine oral bacterial strains were obtained from the American Type Culture Collection 126 (ATCC, Manassas, VA) and 9 oral bacterial strains were kindly given by BEI Resources (managed by 127 ATCC) (Table 1). One colony per bacterial strain was inoculated into $40 \mathrm{ml}$ Brain Heart Infusion (BHI) 128 broth or modified BHI broth in a 50-ml Falcon centrifuge tube, grown at $37{ }^{\circ} \mathrm{C}$ overnight in different 129 atmospheres (Table 1), and used as a seed culture. The bacterial seed culture was inoculated into $2 \mathrm{ml}$ 130 (final volume) of medium with 1,5 , or $10 \%$ (v/v) inoculum in a $15 \mathrm{ml}$ Falcon tube, which contained 131 different concentrations of STAEs or TSNAs in an anaerobic chamber (Coy Laboratory Products INC., 132 Grass, $\mathrm{MI}$ ) with an anaerobic gas mixture, $85 \% \mathrm{~N}_{2}-10 \% \mathrm{H}_{2}-5 \% \mathrm{CO}_{2}$. Then the cultures were incubated 133 at $37{ }^{\circ} \mathrm{C}$ without agitation (Table 1$)$. After 24 (18 h for 6 strains which were grew rapidly) and $48 \mathrm{~h}(36$ $134 \mathrm{~h}$ for the strains which were grew rapidly) incubation, the cultures were collected for bacterial cell 135 growth and viability assays as described below. All experiments were done in triplicate.

\subsection{Assessment of bacterial growth and cell viability}


139 flow cytometer, San Jose, CA) [31, 32]. Samples collected from the bacterial cultures were stained

140 according to the manufacturer's instructions using the LIVE/DEAD BacLight Bacterial Viability and

141 Counting Kit (Life Technologies). Ten microliters of bacterial culture were added into a mixture of 987

$142 \mu \mathrm{l}$ of $0.85 \% \mathrm{NaCl}, 1.5 \mu \mathrm{l}$ of $3.34 \mathrm{mM}$ SYTO 9 nucleic acid stain and $1.5 \mu \mathrm{l}$ of $30 \mathrm{mM}$ propidium iodide

143 in a flow cytometry analysis tube, and then incubated for $15 \mathrm{~min}$ at room temperature, protected from

144 light. Green and red fluorescence were recorded in the FL1 channel (530 $\pm 15 \mathrm{~nm})$ and the FL3 channel

145 (> $670 \mathrm{~nm}$ ), respectively. All parameters were collected as logarithmic. The flow rate was kept below

1465,000 events per second and at least 20,000 cells for each sample were counted. Data were analyzed

147 using CFlow Plus software (Accuri Cytometers). In the density plots of light-scattering properties,

148 bacterial cells were gated from irrelevant counts. In the density plots of fluorescence, the distinct

149 bacterial populations (P1: live cells and P2: dead cells) were gated based on the different viability

150 stages. Cell viability $(\%)=$ percent of P1 (green cells)/(percent of P1 + percent of P2 (red cells)) X 100.

151 Cell Viability Changes $=$ Cell Viability in presence of STAE - Cell Viability in absence of STAE. Total cell numbers

152 = live cell numbers + dead cell numbers. Accuri C6 flow cytometry was calibrated using 8-peak

153 Spherotech Validation Beads.

154

$155 \quad 2.6$ Statistical analysis

156 Student's T-test was employed for analyzing cell growth and cell viability data from triplicated

157 culture samples. For cell growth, cell number is the mean of $\log _{10}$ cell number measured by flow 158 cytometry from triplicated incubations $(\mathrm{SD}<0.10, P$ values $<0.05)$. Cell viability is the mean 159 percentage measured by flow cytometry from triplicate incubations (SD $\leqslant 5 \%, P$ values $<0.05$ ).

160

161 3. Results and discussion 


\subsection{Effects of STAEs on the cell growth of oral bacteria}

163

164

165

166

167

168

169

170

171

172

173

174

175

176

177

178

179

180

181

182

183

184

185

Nicotine is the primary addictive and dependence producing substance in smokeless tobacco products, and nicotine dependence drives the development and maintenance of addiction to tobacco products (https://profiles.nlm.nih.gov/ps/access/NNBBFC.pdf). To determine nicotine level, seven brands of STPs were extracted with aqueous phase, and then were examined with HPLC. Nicotine data were summarized in Table 2. The 38 oral bacterial strains used in the current study are normal inhabitants of the human oral cavity but have sometimes been implicated in cases of periodontitis or other oral disease. Therefore these bacterial strains can be considered as opportunistic pathogens [810]. In our preliminary experiment, we found that artificial saliva [33] did not significantly affect the extraction rate of STAE comparing the extraction with water. The aqueous extraction condition is more similar to chewing extraction conditions in the human mouth than organic solvent extraction condition, thus STAEs were used to investigate effects of STPs on the growth and viability of oral bacteria. The doses of $\operatorname{STAE}(1,10,50 \mathrm{mg} / \mathrm{ml})$ used in this study are similar to physiological conditions in the mouth of the smokeless tobacco users $[34,35]$. Exposure to STAEs affected the growth of all tested strains in a concentration-dependent manner, although there were strain-to-strain variations (Fig. 1, Fig.2). In the presence of $1 \mathrm{mg} / \mathrm{ml}$ STAEs, the growth of 4 strains was inhibited $0.3-2.14 \log _{10}$ fold, while the growth of 14 strains was enhanced $0.3-1.76 \log _{10}$ fold by some of the tested STPs, and the growth of 21 strains was not significantly affected (Fig.1, Fig. 2 and Table S1). A concentration of $1 \mathrm{mg} / \mathrm{ml}$ STAEs from all seven STPs inhibited the growth of Propionibacterium acnes, but promoted the growth of Streptococcus constellatus and S. sanguinis.

In the presence of $10 \mathrm{mg} / \mathrm{ml}$ STAEs, the growth of 17 strains was inhibited $0.3-2.11 \log _{10}$ fold by some of the tested STPs, the growth of 18 strains was enhanced $0.3-0.94 \log _{10}$ fold by some of the tested STPs, and the growth of 4 strains were not affected (Fig.1, Fig. 2 and Table S1). At 10 mg/ml, STAEs from all seven STPs inhibited the growth of 4 strains, including Aggregatibacter 
actinomycetemcomitans, Actinomyces naeslundii, Eikenella corrodens, and Fusobacterium nucleatum;

187 and promoted the growth of 7 strains, including Eubacterium nodatum, Gemella morbillorum,

188 Peptostreptococcus micros, Streptococcus anginosus, S. constellatus, S. sanguinis, and Veillonella 189 parvula.

190 In the presence of $50 \mathrm{mg} / \mathrm{ml}$ STAEs, the growth of 32 strains was inhibited $0.3-2.96 \log _{10}$ fold by 191 some of the tested STPs, the growth of 8 strians was enhanced $0.3-1 \log _{10}$ fold by some of the tested 192 STPS, and 2 strains were not significantly affected after 18-48 h (Fig.1, Fig. 2 and Table S1). The 50 193 $\mathrm{mg} / \mathrm{ml}$ concentration of STAEs from all seven STPs inhibited the growth of 21 strains and only 194 promoted the growth of E. nodatum.

195 At a low concentration of STAEs $(1 \mathrm{mg} / \mathrm{ml})$, the growth of more than half of the tested bacterial 196 strains was not significantly affected. With increasing concentrations of STAEs from 1 to $50 \mathrm{mg} / \mathrm{ml}$, the number of bacterial strains whose growth was enhanced increased at first, and then decreased, which might be due to the conflicting effects of nutrients and toxic compounds in STPs. At a high concentration of STAEs $(50 \mathrm{mg} / \mathrm{ml})$, the growth of most strains was inhibited. Similar to the results of contributes to development of caries and periodontal disease [36]. In addition to S. sanguinis, we also

nodatum has strong association with periodontitis, whether in the presence or absence of high levels of the consensus pathogens [14]. S. anginosus was associated with oral infection [37], liver abscesses [38], and esophageal cancer [39]. STAEs promoted the growth of these bacterial species associated 
211 tobacco ingredients could disrupt the oral ecology and enhance the risk of oral disease.

212 When incubated for 18 or $24 \mathrm{~h}$, there were 22 and 19 strains inhibited by $50 \mathrm{mg} / \mathrm{ml}$ STAE of Snus 2131 (Camel Snus Large Robust) and 2 (Marlboro Snus Mint), respectively; on the other hand, there were 21426 -30 strains inhibited by STAEs from five brands of snuffs for more than two fold, which implies that 215 the snuffs may be more harmful to the oral bacteria than snus.

\subsection{Effects of STAEs on the cell viability of oral bacteria}

218 To investigate whether STAEs could affect the cell viability of oral bacteria, cell viabilities of 38 219 oral bacterial strains grown with or without STAEs were determined by flow cytometry measurements. 220 STAEs decreased cell viability (20.3-93.3\%) for 27 strains in a concentration-dependent manner (Fig. 3 and Table S2). In the presence of $1 \mathrm{mg} / \mathrm{ml} \mathrm{STAEs,} \mathrm{the} \mathrm{viability} \mathrm{of} 4$ strains decreased 21.1-66.5\%; in the presence of $10 \mathrm{mg} / \mathrm{ml}$ STAEs, that of 9 strains decreased $20.3-85.7 \%$; in the presence of $50 \mathrm{mg} / \mathrm{ml}$ STAEs, viability of 27 strains decreased 22.0-93.3\%. Cell viabilities of four bacterial strains were slightly reduced (10.5-19.8\%) by STAEs from some of the tested STPs. STAEs slightly enhanced cell 225 viability (10.2-15.7\%) for four strains, including F. nucleatum, Fusobacterium periodonticum, and G. morbilorum, and Treponema socranskii at $1 \mathrm{mg} / \mathrm{ml}$ or $10 \mathrm{mg} / \mathrm{ml}$. STAEs from all seven STPs had no significant effect on the cell viability of 7 strains, including B. forsythus, Campylobacter rectus, studies indicate that $B$. forsythus, E. nodatum, T. socranskii are associated with periodontal disease [40]; other organ abscesses [38, 42]. 


\subsection{Effects of TSNAs on the cell growth and viability of oral bacteria}

TSNAs are considered the most important carcinogens in STPs [23, 24]. However, few studies

235

236

237

238

239

240

241

242

243

244

245

246

247

248

249

250

251

252

253

254

255

256

investigated effects of TSNAs on the growth and viability of oral bacteria. Three important TSNAs (NNN, NNK, and NNAL) were added to bacterial cultures to investigate the effects on the cell growth and viability of 38 oral bacteria species/subspecies by flow cytometry measurements. Cell growth of 24 strains was not significantly affected by tested TSNAs (Fig. 4 and Table S3), P. micros was enhanced 0.10-0.54 $\log _{10}$ fold by all three TSNAs, and cell growth of 12 other strains was enhanced 0.1-0.26 $\log _{10}$ fold, including C. sputigena and Porphyromonas gingivalis (Fig. 4 and Table S3). The three strains, $C$. sputigena, $P$. micros and $P$. gingivalis, are all potentially associated with periodontal disease $[11,13,43]$. Cell growth of $V$. parvula was inhibited with a decrease of $0.33-0.36 \log _{10}$ fold, and 2 other strains slightly decreased $\left(0.10-0.13 \log _{10}\right.$ fold) (Fig. 4). In general, cell growth of the oral bacteria was not significantly affected by TNSAs at the tested concentrations. For cell viability, 32 of 38 strains were not significantly affected by TSNAs (Fig. 5 and Table S4). Cell viabilities of C. rectus and $F$. periodonticum decreased 56.6-69.9\%, and 4 other strains were slightly decreased (11.0-19.8\%). As TSNAs are well known to be important carcinogens in STPs [23, 24], use of STPs may have negative effects on oral health. Similar as above, cell viability for the oral bacteria was not significantly affected by TSNAs at the tested concentrations, indicating that other ingredients in the smokeless tobacco products may be the responsible for the growth inhibition and decreasing cell viability of the bacteria.

\section{Conclusions}

STAEs affected the growth and viability of some oral bacterial species in a concentrationdependent manner. Among the bacterial species in which the growth rate was enhanced by STAEs, some were associated with opportunistic pathogens which potentially cause oral diseases (e.g., gingival 
and periodontal inflammation and dental caries). STAEs from snuffs inhibited more bacterial strains than those from snus indicating that the snuffs may be more toxic to the oral bacteria than snus. Our results indicate that STPs might have adverse effects on maintaining a healthy ecological balance of oral bacteria in humans. Since the human oral microbiome is a diverse and complex ecosystem, future research to evaluate the toxicological effects of smokeless tobacco on the oral microbiota in vivo and the genotoxicity of smokeless tobacco products and their metabolites produced by oral microbiota, which may provide new insight into how smokeless tobacco causes diseases, is warranted. The new insights from this study might contribute to the understanding of the interactions of oral microbiome and smokeless tobacco. The methodology described in this study could potentially be used as an effective assay to compare the relative toxicity of various smokeless tobacco products on oral bacteria.

\section{Acknowledgements}

We thank Drs. John Sutherland, Steven Foley and Hans Rosenfeldt for their critical review of this manuscript. We also thank CTP writer Mrs. Deborah Neveleff for proof reading the manuscript. This study was funded by the Center for Tobacco Products, U.S. Food and Drug Administration (E0747201), and supported in part by appointment (M.L., H.P., J.J., and J.F.) to the Postgraduate Research Fellowship Program by the Oak Ridge Institute for Science and Education through an interagency agreement between the U.S. Department of Energy and the U.S. Food and Drug Administration. The authors thank Mrs. Jinyan Sun for technical assistance with growth of bacterial cultures. The findings and conclusions in this publication are those of the authors and do not represent FDA positions or policies.

Figure legends

Figure 1 The cell growth of oral bacteria incubated with STAEs from different STP brands for 18 
number change $\geq 0.3 \log _{10}$, the change is considered as significant. A: incubated with STAE from Snus 2831 (Camel Snus Large Robust); B: incubated with STAE from Snus 2 (Marlboro Snus Mint); C: 284 incubated with STAE from Snuff 3 (Copenhagen Snuff Original Fine Cut); D: incubated with STAE 285 from Snuff 4 (Copenhagen Long Cut Wintergreen); E: incubated with STAE from Snuff 5 (Grizzly 286 Long Cut Premium Wintergreen); F: incubated with STAE from Snuff 6 (Skoal Long Cut Classic 287 Wintergreen); G: incubated with STAE from Snuff 7 (Skoal Banditis Wintergreen). Statistically 288 significant values were presented here, the rest dada were shown in Table S1. * Strains were incubated for $18 \mathrm{~h}$, while other strains were incubated for $24 \mathrm{~h}$.

Figure 2 The cell growth changes of oral bacteria incubated with STAEs from different STP

brands for 36 or $48 \mathrm{~h}$. The cell number change = Cell Number in presence of STAE/ Cell Number in absence of

STAE. When cell number change $\geq 0.3 \log _{10}$, the change is considered as significant. A: incubated with

STAE from Snus 1 (Camel Snus Large Robust); B: incubated with STAE from Snus 2 (Marlboro Snus

Mint); C: incubated with STAE from Snuff 3 (Copenhagen Snuff Original Fine Cut); D: incubated with

STAE from Snuff 4 (Copenhagen Long Cut Wintergreen); E: incubated with STAE from Snuff 5

(Grizzly Long Cut Premium Wintergreen); F: incubated with STAE from Snuff 6 (Skoal Long Cut

Classic Wintergreen); G: incubated with STAE from Snuff 7 (Skoal Banditis Wintergreen). Statistically significant values were presented here, the rest dada were shown in Table S1. * Strains were incubated for $36 \mathrm{~h}$, while other strains were incubated for $48 \mathrm{~h}$.

Figure 3 The cell viability changes of oral bacteria incubated with STAE from different STP

brands. Cell Viability Changes $=$ Cell Viability in presence of STAE - Cell Viability in absence of STAE. When cell viability change $\geq 20 \%$, the change is considered as significant. A: incubated with STAE from Snus 1 (Camel Snus Large Robust); B: incubated with STAE from Snus 2 (Marlboro Snus Mint); C: incubated 
307 (Copenhagen Long Cut Wintergreen); E: incubated with STAE from Snuff 5 (Grizzly Long Cut 308 Premium Wintergreen); F: incubated with STAE from Snuff 6 (Skoal Long Cut Classic Wintergreen); 309 G: incubated with STAE from Snuff 7 (Skoal Banditis Wintergreen). * Strains were incubated for $18 \mathrm{~h}$, 310 while other strains were incubated for $24 \mathrm{~h}$.

312 Figure 4 The cell growth changes of oral bacteria incubated with TSNAs. The cell number change $313=$ Cell Number in presence of STAE $/$ Cell Number in absence of STAE. When cell number change $\geq 0.3 \log _{10}$, the 314 change is considered as significant. A: incubated with NNN for $24 \mathrm{~h}$; B: incubated with NNAL for 24 315 h; C: incubated with NNK for 24 h; D: incubated with NNN for 48 h; E: incubated with NNAL for 48 $316 \mathrm{~h}$; F: incubated with NNK for $48 \mathrm{~h}$. * Strains were incubated for $18 \mathrm{~h}$; $\uparrow$ strains were incubated for $36 \mathrm{~h}$.

318 Figure 5 The cell viability changes of oral bacteria incubated with TSNAs. Cell Viability Changes $319=$ Cell Viability in presence of STAE - Cell Viability in absence of STAE. A: incubated with NNN for 24 h; B: 320 incubated with NNAL for $24 \mathrm{~h}$; C: incubated with NNK for $24 \mathrm{~h}$. * Strains were incubated for $18 \mathrm{~h}$. 
1. Agaku IT, King BA, Husten CG, Bunnell R, Ambrose BK, Hu SS, Holder-Hayes E, Day HR, Centers for Disease C, Prevention: Tobacco product use among adults--United States, 20122013. MMWR Morb Mortal Wkly Rep 2014, 63(25):542-547.

2. Critchley JA, Unal B: Health effects associated with smokeless tobacco: a systematic review. Thorax 2003, 58(5):435-443.

3. Greer Jr RO: Oral manifestations of smokeless tobacco use. Otolaryngologic Clinics of North America 2011, 44(1):31-56.

4. Boffetta P, Hecht S, Gray N, Gupta P, Straif K: Smokeless tobacco and cancer. The Lancet Oncology 2008, 9(7):667-675.

5. Humans IWGotEoCRt: Smokeless tobacco and some tobacco-specific N-nitrosamines. IARC Monogr Eval Carcinog Risks Hum 2007, 89:1-592.

6. Hoffmann D, Djordjevic MV: Chemical composition and carcinogenicity of smokeless tobacco. Advances in Dental Research 1997, 11(3):322-329.

7. Richter P, Spierto FW: Surveillance of smokeless tobacco nicotine, $\mathbf{p H}$, moisture, and unprotonated nicotine content. Nicotine \& Tobacco Research 2003, 5(6):885-889.

8. Kirst ME, Li EC, Alfant B, Chi YY, Walker C, Magnusson I, Wang GP: Dysbiosis and alterations in predicted functions of the subgingival microbiome in chronic periodontitis. Applied and environmental microbiology 2015, 81(2):783-793.

9. Paster BJ, Olsen I, Aas JrA, Dewhirst FE: The breadth of bacterial diversity in the human periodontal pocket and other oral sites. Periodontology 2000 2006, 42(1):80-87.

10. Aas JrA, Paster BJ, Stokes LN, Olsen I, Dewhirst FE: Defining the normal bacterial flora of the oral cavity. Journal of Clinical Microbiology 2005, 43(11):5721-5732.

11. Jenkinson HF, Lamont RJ: Oral microbial communities in sickness and in health. Trends in microbiology 2005, 13(12):589-595.

12. Nagarajappa S, Prasad KV: Oral microbiota, dental caries and periodontal status in smokeless tobacco chewers in Karnataka, India: a case-control study. Oral health \& preventive dentistry 2010, 8(3):211-219.

13. Kesic L, Milasin J, Igic M, Obrodovic R: Microbial etiology of periodontal disease-mini review. Med Biol 2008, 15:1-6.

14. Haffajee A, Teles R, Socransky S: Association of Eubacterium nodatum and Treponema denticola with human periodontitis lesions. Oral microbiology and immunology 2006, 21(5):269-282.

15. Keene K, Johnson RB: The effect of nicotine on growth of Streptococcus mutans. Mississippi Dental Association Journal 1999, 55(4):38-39.

16. Huang R, Li M, Gregory RL: Effect of nicotine on growth and metabolism of Streptococcus mutans. European Journal of Oral Sciences 2012, 120(4):319-325.

17. Lindemeyer RG, Baum RH, Hsu SC, Going RE: In vitro effect of tobacco on the growth of oral cariogenic streptococci. The Journal of the American Dental Association 1981, 103(5):719-722.

18. Tomar SL, Winn DM: Chewing tobacco use and dental caries among US men. The Journal of the American Dental Association 1999, 130(11):1601-1610.

19. Jacks SC, Schroeder KL, Rosen S: In vitro effects of smokeless tobacco on cariogenic $\mathbf{L}$. casei (abstract 1668). J Dent Res 1989, 68:390. 
20. Falkler WA, Zimmerman ML, Martin SA, Hall ER: The effect of smokeless-tobacco extracts on the growth of oral bacteria of the genus Streptococcus. Archives of Oral Biology 1987, 32(3):221-223.

21. Ayo-Yusuf OA, Van Wyk C, Van Wyk CW, De Wet I: Smokeless tobacco products on the South African market do not inhibit oral bacterial flora: a pilot study. Southern African Journal of Epidemiology and Infection 2005, 20(4):136-139.

22. IARC: IARC Monographs on the Evaluation of Carcinogenic Risks to Humans, vol. 89. Lyon, France: International Agency for Research on Cancer; 2007.

23. Hecht SS: Biochemistry, biology, and carcinogenicity of tobacco-specific N-nitrosamines. Chemical research in toxicology 1998, 11(6):559-603.

24. Hecht SS, Hoffmann D: Tobacco-specific nitrosamines, an important group of carcinogens in tobacco and tobacco smoke. Carcinogenesis 1988, 9(6):875-884.

25. Rodu B, Jansson C: Smokeless tobacco and oral cancer: a review of the risks and determinants. Critical reviews in oral biology and medicine : an official publication of the American Association of Oral Biologists 2004, 15(5):252-263.

26. Maxwell JCJ: The smokeless tabacco industries 2011. The Maxwell Report 2012:1-10.

27. Delnevo CD, Wackowski OA, Giovenco DP, Manderski MT, Hrywna M, Ling PM: Examining market trends in the United States smokeless tobacco use: 2005-2011. Tob Control 2014, 23(2):107-112.

28. Jansson T, Romert L, Magnusson J, Jenssen D: Genotoxicity testing of extracts of a Swedish moist oral snuff. Mutation Research 1991, 261(2):101-115.

29. Shirnamé-Moré L: Forward mutation of S. typhimurium by smokeless tobacco extracts. Mutation Research/Genetic Toxicology 1991, 259(1):37-42.

30. Massadeh AM, Gharaibeh AA, Omari KW: A single-step extraction method for the determination of nicotine and cotinine in Jordanian smokers' blood and urine samples by RP-HPLC and GC-MS. Journal of chromatographic science 2009, 47(2):170-177.

31. Pan H, Feng J, Cerniglia CE, Chen H: Effects of Orange II and Sudan III azo dyes and their metabolites on Staphylococcus aureus. Journal of industrial microbiology \& biotechnology 2011, 38(10):1729-1738.

32. Pan H, Feng J, He GX, Cerniglia CE, Chen H: Evaluation of impact of exposure of Sudan azo dyes and their metabolites on human intestinal bacteria. Anaerobe 2012, 18(4):445-453.

33. Ionta FQ, Mendonca FL, de Oliveira GC, de Alencar CR, Honorio HM, Magalhaes AC, Rios D: In vitro assessment of artificial saliva formulations on initial enamel erosion remineralization. Journal of dentistry 2014, 42(2):175-179.

34. Ferketich AK, Wee AG, Shultz J, Wewers ME: Smokeless tobacco use and salivary cotinine concentration. Addictive behaviors 2007, 32(12):2953-2962.

35. Mushtaq N, Beebe LA, Vesely SK: Determinants of salivary cotinine concentrations among smokeless tobacco users. Nicotine \& tobacco research : official journal of the Society for Research on Nicotine and Tobacco 2012, 14(10):1229-1234.

36. Kolenbrander PE, London J: Adhere today, here tomorrow: oral bacterial adherence. Journal of Bacteriology 1993, 175(11):3247-3252.

37. Bancescu G, Dumitriu S, Bancescu A, Skaug N: Streptococci species of anginosus group isolated from oral and maxillofacial infections. Roumanian archives of microbiology and immunology 1999, 58(1):49-55.

38. Cellucci M, Simon E, Eppes S: Microbiology and Management of Pediatric Liver Abscesses: Two Cases Caused by Streptococcus anginosus Group. Case reports in infectious diseases 2012, 2012:685953.

39. Morita E, Narikiyo M, Yano A, Nishimura E, Igaki H, Sasaki H, Terada M, Hanada N, Kawabe $\mathrm{R}$ : Different frequencies of Streptococcus anginosus infection in oral cancer and 
esophageal cancer. Cancer science 2003, 94(6):492-496.

40. Hasebe A, Yoshimura A, Into T, Kataoka H, Tanaka S, Arakawa S, Ishikura H, Golenbock DT, Sugaya T, Tsuchida N et al: Biological activities of Bacteroides forsythus lipoproteins and their possible pathological roles in periodontal disease. Infection and immunity 2004, 72(3):1318-1325.

41. Mahlen SD, Clarridge JE, 3rd: Oral abscess caused by Campylobacter rectus: case report and literature review. Journal of clinical microbiology 2009, 47(3):848-851.

42. Solanki R, Subramanian S, Lakshmi V, Bhushanam V, Kumar A: Brain abscess due to Streptococcus oralis in an immunocompetent patient. Indian journal of medical microbiology 2014, 32(2):179-180.

43. Mayanagi G, Sato T, Shimauchi H, Takahashi N: Detection frequency of periodontitisassociated bacteria by polymerase chain reaction in subgingival and supragingival plaque of periodontitis and healthy subjects. Oral microbiology and immunology 2004, 19(6):379385. 
Figure

Fig. 1

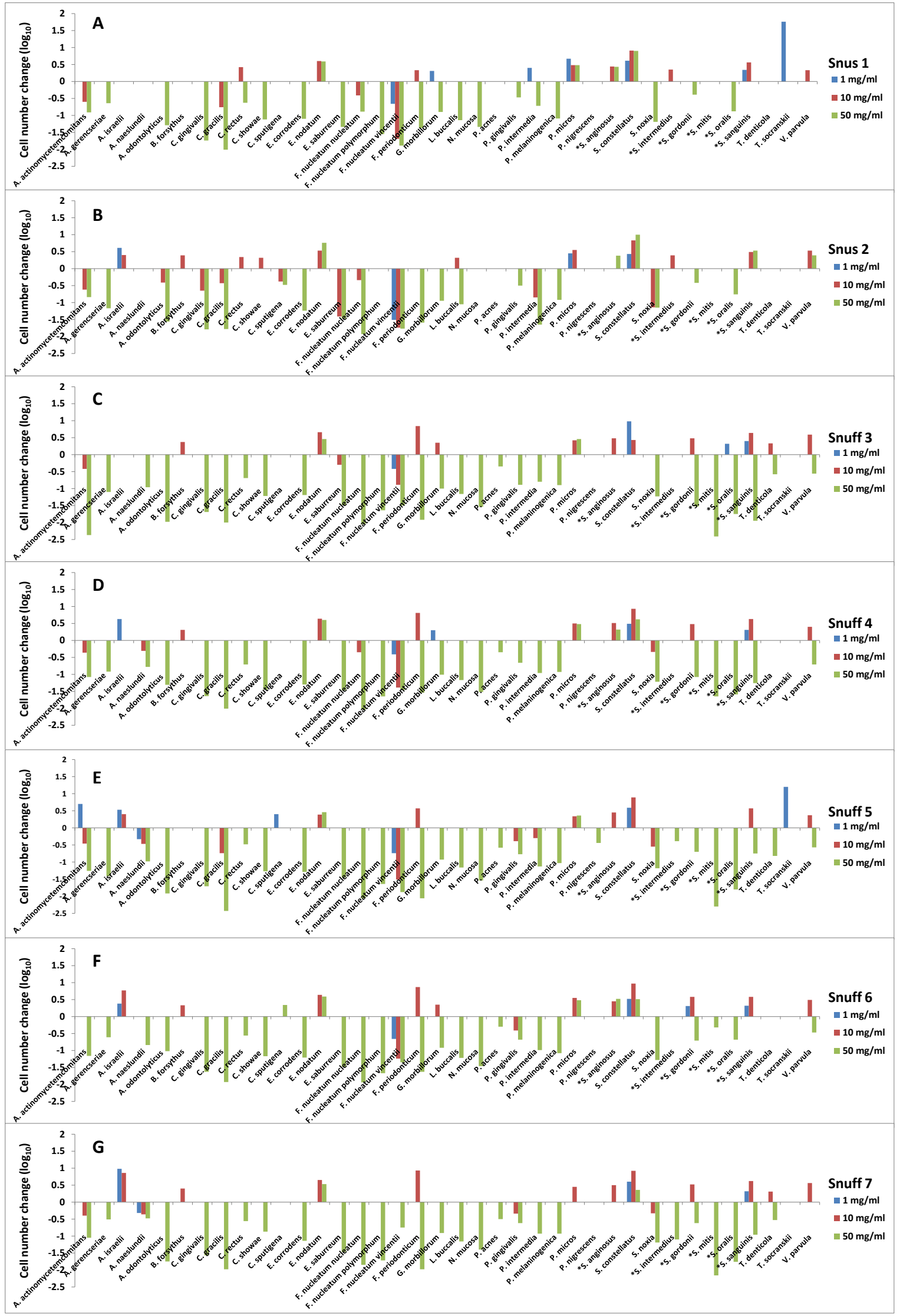


Fig. 2

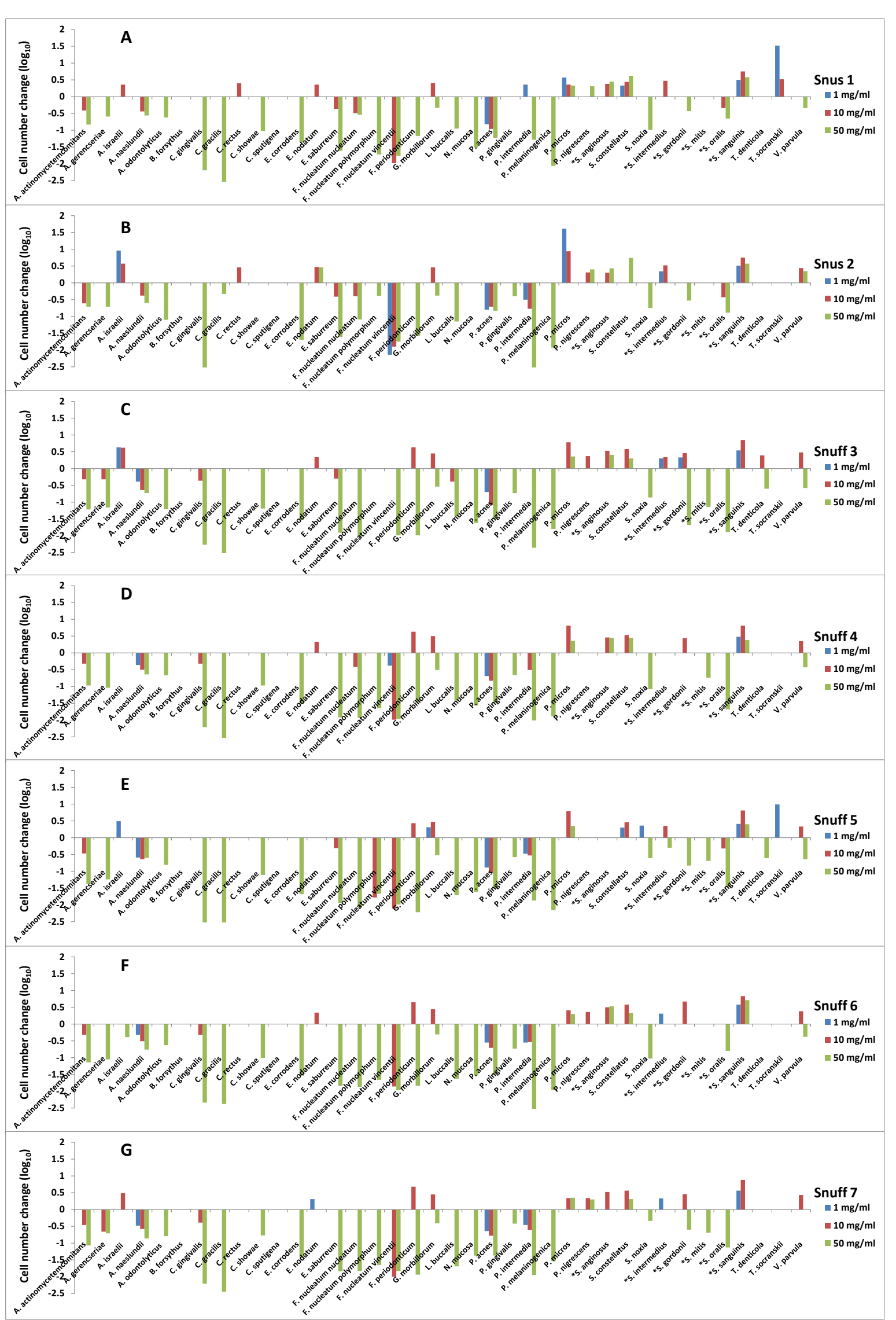


Figure

Fig. 3

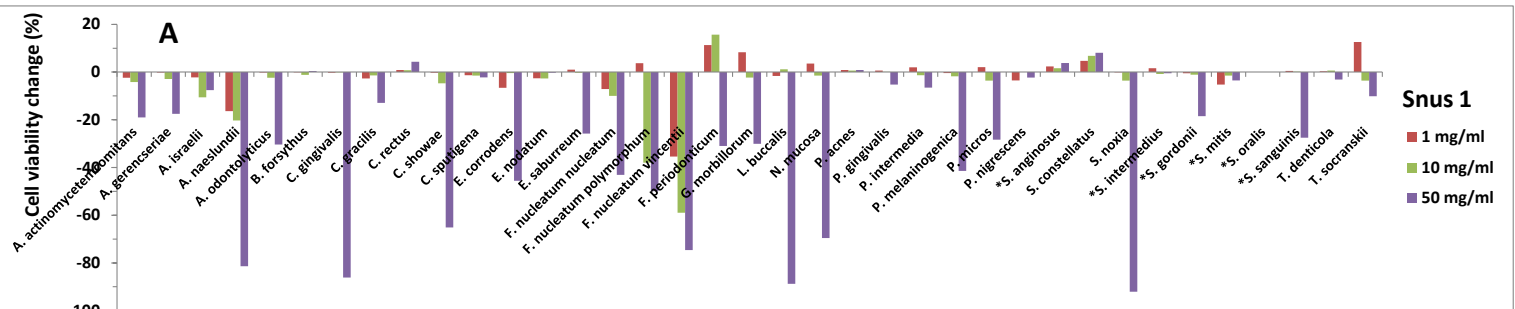

.

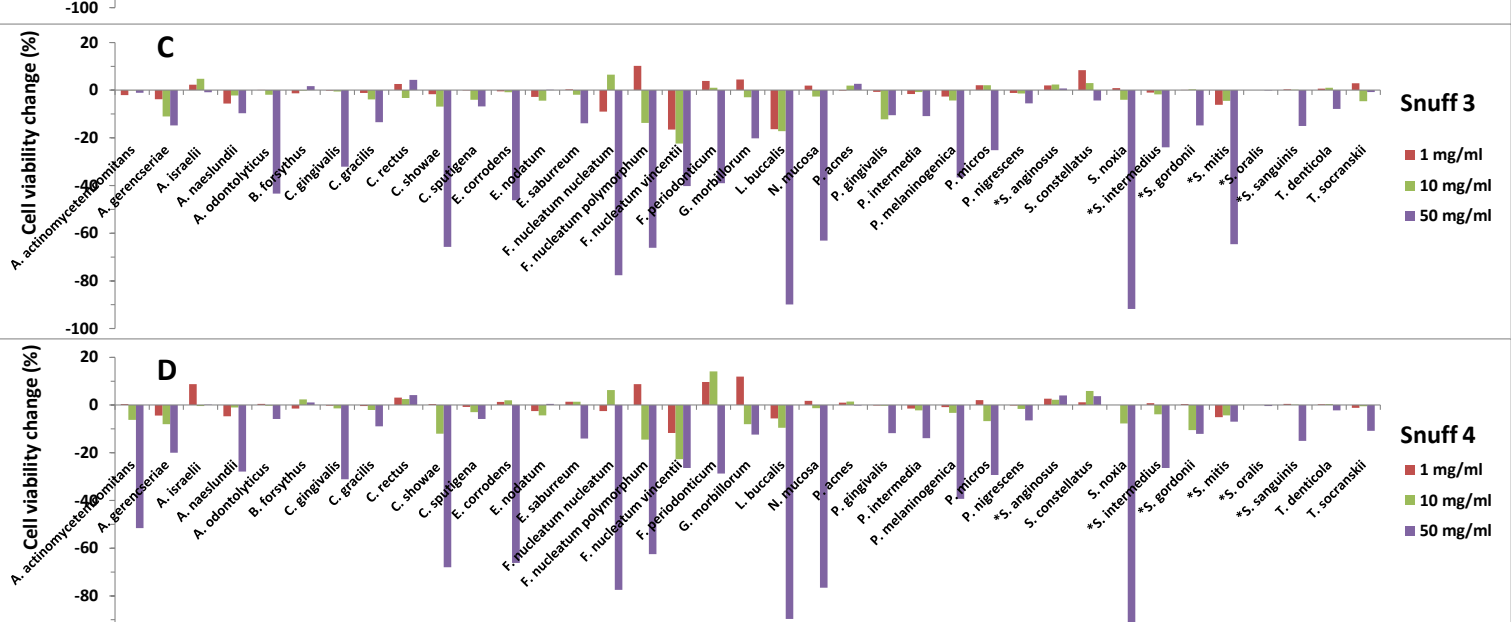

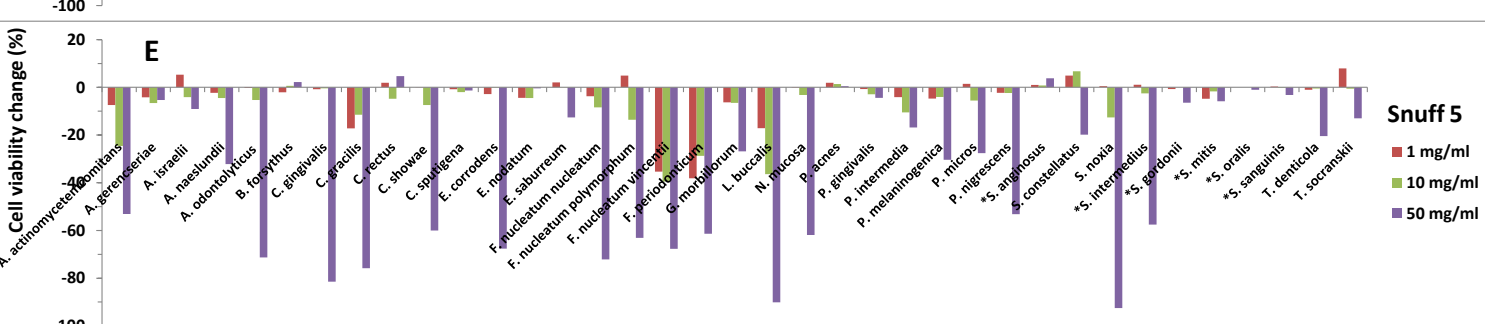

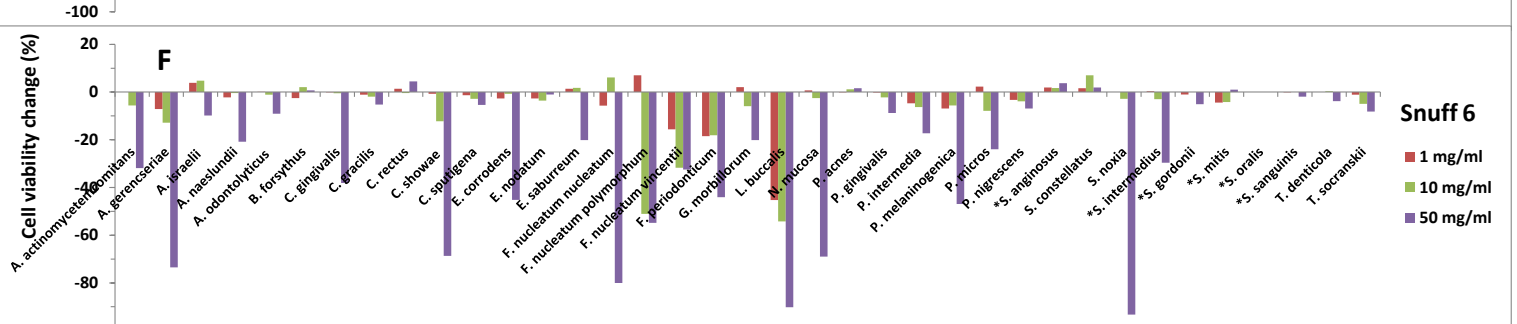

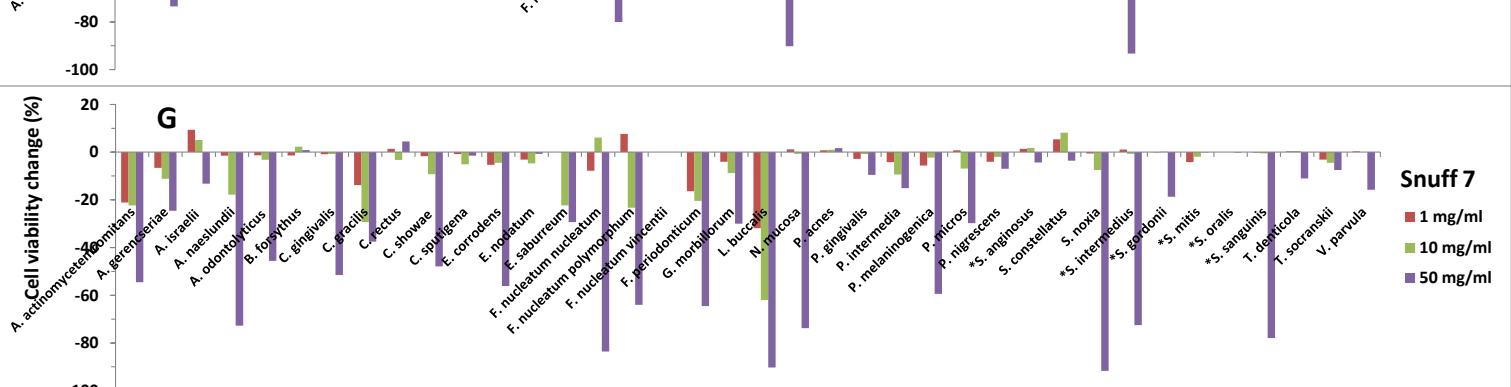


Figure

Fig. 4

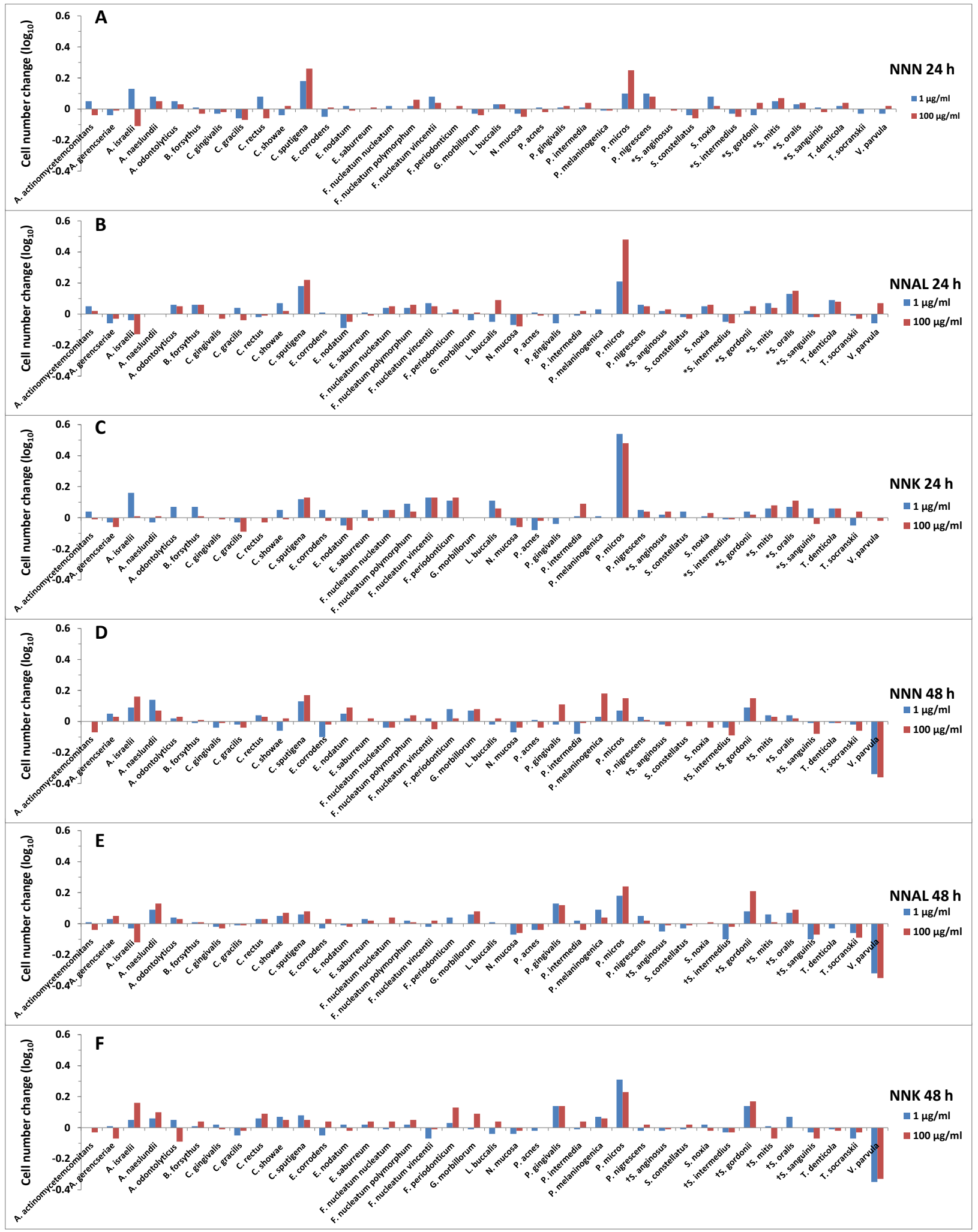


Figure

Fig. 5

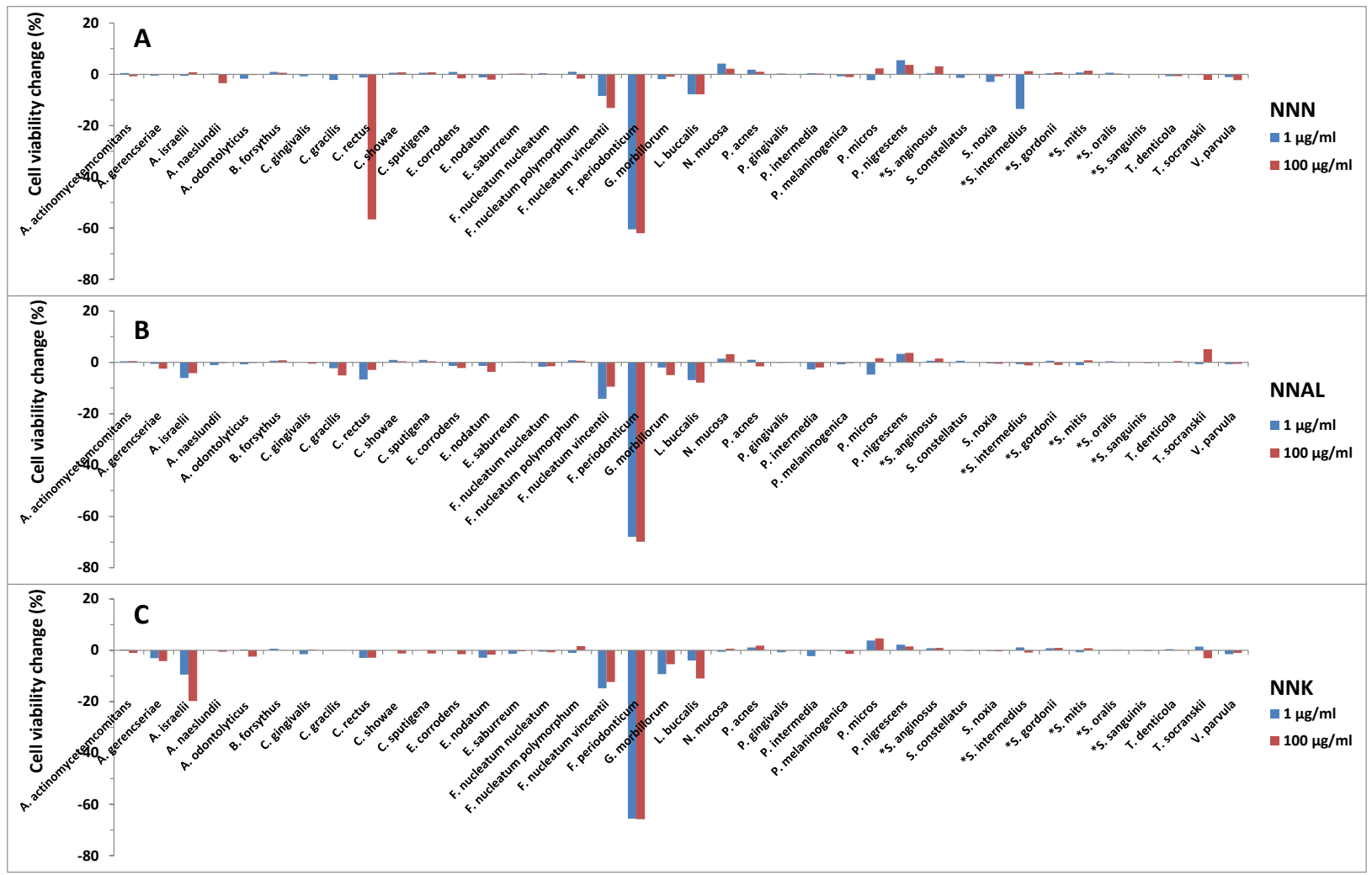


Table 1. The oral bacterial strains and culture conditions used in the study

\begin{tabular}{|c|c|c|c|c|}
\hline Strain name & Culture medium ${ }^{\mathrm{a}}$ & Inoculum (\%) & Atmosphere & Source \\
\hline Aggregatibacter actinomycetemcomitans ATCC 29524 & BHI & 5 & $\mathrm{CO}_{2}(5 \%)$ & ATCC \\
\hline Actinomyces gerencseriae F0344 & BYKH & 5 & Anaerobic & BEI \\
\hline Actinomyces israelii $\mathrm{F} 0345$ & BHI & 10 & Anaerobic & BEI \\
\hline Actinomyces naeslundii ATCC 12104 & BHI & 5 & Anaerobic & ATCC \\
\hline Actinomyces odontolyticus $\mathrm{F} 0309$ & BYKH & 5 & Anaerobic & BEI \\
\hline Bacteroides forsythus ATCC 43037 & BHI & 10 & Anaerobic & ATCC \\
\hline Capnocytophaga gingivalis ATCC 33624 & BHI & 1 & Anaerobic & ATCC \\
\hline Campylobacter gracilis ATCC 33236 & BHIFF & 5 & Anaerobic & ATCC \\
\hline Campylobacter rectus ATCC 33238 & BHIFF & 5 & Anaerobic & ATCC \\
\hline Campylobacter showae ATCC 51146 & BHIFF & 5 & Anaerobic & ATCC \\
\hline Capnocytophaga sputigena ATCC 33612 & BHI & 5 & Anaerobic & ATCC \\
\hline Eikenella corrodens ATCC 23834 & BHI & 5 & $\mathrm{CO}_{2}(5 \%)$ & ATCC \\
\hline Eubacterium nodatum ATCC 33099 & BYKH & 1 & Anaerobic & ATCC \\
\hline Eubacterium saburreum ATCC 43850 & $\mathrm{BHI}$ & 1 & Anaerobic & ATCC \\
\hline Fusobacterium nucleatum nucleatum ATCC 23726 & BHI & 1 & Anaerobic & ATCC \\
\hline Fusobacterium nucleatum polymorphum F0401 & BHI & 1 & Anaerobic & BEI \\
\hline Fusobacterium nucleatum vincentii ATCC 49256 & BHI & 1 & Anaerobic & ATCC \\
\hline Fusobacterium periodonticum ATCC 33693 & BHI & 1 & Anaerobic & ATCC \\
\hline Gemella morbillorum M424 & BYKH & 10 & Anaerobic & BEI \\
\hline Leptotrichia buccalis ATCC 14201 & BHI & 1 & Anaerobic & ATCC \\
\hline Neisseria mисова $\mathrm{C} 102$ & BYKHL & 5 & Anaerobic & BEI \\
\hline Propionibacterium acnes ATCC 6919 & BYKHL & 1 & Anaerobic & ATCC \\
\hline Porphyromonas gingivalis ATCC 33277 & TSB-YKHL & 1 & Anaerobic & ATCC \\
\hline Prevotella intermedia ATCC 25611 & TSB-YKHL & 5 & Anaerobic & ATCC \\
\hline Prevotella melaninogenica ATCC 25845 & $\mathrm{BHI}$ & 10 & Anaerobic & ATCC \\
\hline Peptostreptococcus micros ATCC 33270 & BHI & 5 & Anaerobic & ATCC \\
\hline Prevotella nigrescens ATCC 33563 & BHI & 10 & Anaerobic & ATCC \\
\hline Streptococcus anginosus $\mathrm{F} 0211$ & BHI & 5 & Anaerobic & BEI \\
\hline Streptococcus constellatus ATCC 27513 & BHI & 5 & Anaerobic & ATCC \\
\hline Selenomonas noxia 43527 & BYKHL & 1 & Anaerobic & BEI \\
\hline Staphylococcus intermedius ATCC 51874 & BHI & 5 & Anaerobic & ATCC \\
\hline Streptococcus gordonii ATCC 33399 & BHI & 5 & Anaerobic & ATCC \\
\hline Streptococcus mitis ATCC 903 & BHI & 5 & Anaerobic & ATCC \\
\hline Streptococcus oralis ATCC 35037 & BHI & 5 & Anaerobic & ATCC \\
\hline Streptococcus sanguinis ATCC 29667 & BHI & 5 & Anaerobic & ATCC \\
\hline Treponema denticola 33520 & BHI & 5 & Anaerobic & BEI \\
\hline Treponema socranskii ATCC 35535 & BHI & 10 & Anaerobic & ATCC \\
\hline Veillonella parvula ATCC 17745 & BHI & 10 & Anaerobic & ATCC \\
\hline
\end{tabular}

${ }^{a} \mathrm{BHI}$, brain-heart infusion medium; BYKH, brain-heart infusion medium with yeast extract, vitamin $\mathrm{K} 1$ solution and hemin solution; BYKHL, brain-heart infusion medium with yeast extract, vitamin K1 solution, hemin solution and L-cysteine HCl; TSB-YKHL, Tryptic Soy Broth with yeast extract, vitamin K1 solution, hemin solution and L-cysteine HCl; BHIFF, brainheart infusion medium with formate and fumarate. 
Table 2. Nicotine contents in STPs ${ }^{\mathrm{a}}$

\begin{tabular}{cc}
\hline STP $^{\mathrm{b}}$ & Nicotine/STP $(\mathrm{mg} / \mathrm{g})$ \\
\hline Snus 1 & 4.77 \\
Snus 2 & 4.57 \\
Snuff 3 & 6.72 \\
Snuff 4 & 6.00 \\
Snuff 5 & 5.12 \\
Snuff 6 & 5.11 \\
Snuff 7 & 5.03 \\
\hline
\end{tabular}

\footnotetext{
${ }^{a}$ The data were shown in the mean of triplicate (SD $\leq 0.05$ ); ${ }^{b}$ Snus 1 (Camel Snus Large Robust); Snus 2 (Marlboro Snus Mint); Snuff 3 (Copenhagen Snuff Original Fine Cut); Snuff 4 (Copenhagen Long Cut Wintergreen); Snuff 5 (Grizzly Long Cut Premium Wintergreen); Snuff 6 (Skoal Long Cut Classic Wintergreen); Snuff 7 (Skoal Banditis Wintergreen).
} 